\title{
What's All This Hype About Hypertext?: Teaching Literature with George P. Landow's The Dickens Web
}

\author{
Jonathan Smith * \\ Department of Humanities, University of Michigan - Dearborn, Dearborn, MI 48128-1491, USA \\ e-mail: jonsmith@umich.edu
}

Key words: hypertext, hypermedia, Victorian literature, instructional technology, computers, collaborative learning, research education

\begin{abstract}
The essay describes the use of George P. Landow's hypertext, The Dickens Web, in an advanced undergraduate literature class and analyzes its practical and theoretical implications. Hypertext is shown to encourage active student engagement, especially with contextual material; to lead to more focused research topics; and to facilitate student collaboration. Some of Landow's claims about the ease with which this occurs, however, are questioned. The difficulty of teaching students how to follow and construct conceptual hypertextual links is examined, and the instructor's role in relation to student contributions to the Web is presented as much more problematic than Landow allows.
\end{abstract}

George P. Landow is arguably academe's most enthusiastic literary proponent of hypertext and hypermedia. In a series of books and articles he has both explicated hypertext's theoretical dimensions and extolled its pedagogical potential. As teaching tools, hypertext and hypermedia create a student-centered environment in which students become active participants in the construction of knowledge. Two hypertext "webs" that Landow has developed to exploit this potential in his own teaching, The Dickens Web and The In Memoriam $W e b$, are now commercially available, and part of the latter is accessible on the World Wide Web. This paper will describe my use of The Dickens Web in an upper-level undergraduate literature class, assess the strengths and weaknesses of this software in classroom and course-related applications, and comment on some of Landow's theoretical claims about the medium.

\footnotetext{
* Jonathan Smith is Assistant Professor of English at the University of Michigan-Dearborn. His research interests include Victorian literature and science, hypertext, and modern works of scientific popularization. He is the author of Fact and Feeling: Baconian Science and the Nineteenth-Century Literary Imagination (Wisconsin, 1994) and such articles as the forthcoming "Heat and Modern Thought: The Forces of Nature in Our Mutual Friend" in Victorian Literature and Culture.
}

\section{Description of Course and Software}

I teach at the University of Michigan-Dearborn, a regional public university with a primary mission in undergraduate education. Its student population is drawn almost exclusively from the Detroit metropolitan area, especially the middle-class suburbs to the west and southwest of the city. A significant percentage of the students is non-traditional, and all of them are commuters.

I employed The Dickens Web in an upper-level English class on the nineteenth-century British novel. Approximately twenty juniors and seniors, all of them English majors, enrolled. Most of the students took the course to satisfy a period requirement in nineteenthcentury literature rather than to experience a new classroom format. Almost all had used a computer for personal word processing, and while few owned their own computer, many had access to a computer at home. Only three or four, however, had used the campus's computer network for word processing or for e-mail, and none owned a modem or had accessed the Internet.

The course was taught in a classroom equipped with about twenty-five PCs connected to the campus network. An overhead projection device permitted the 
instructor's computer to be displayed on a screen at the front of the room. The software was installed on the hard drives of the individual PCs in the classroom and on some of the PCs in the campus's two primary computer labs, as well as on the campus's main server. Students thus had ready access to the software outside of class; they were encouraged to use the local hard drive versions rather than the "common" copy on the server until they were familiar and comfortable with it.

Storyspace and The Dickens Web are available from Eastgate Systems in both Windows and Macintosh platforms. The combination of bulk and educational discounts make it a feasible, although not an inexpensive, purchase for institutions and students.

The basic unit of the hypertext "webs" constructed from Storyspace is called a "writing space." In what Storyspace refers to as its "map view," a writing space appears as a small box with a title bar across the top. (Other views display the hypertext in chart, outline, and tree map formats.) Writing spaces in turn can contain both "text spaces," in which actual writing and images may appear, as well as other writing spaces. In the latter case, the map view looks like collections of Chinese boxes. Material in the web is connected through both "basic links" and "text links"; basic links connect related writing spaces while text links connect words or phrases in text spaces either to writing spaces or to other bits of text. The user employs a small "toolbar" of icons to create and edit the writing spaces, text spaces, and hypertext links.

The Dickens Web is a Storyspace hypertext and hence is read in the same ways. It contains a wide variety of information on Dickens and Great Expectations, the novel around which it is constructed. The material ranges from biographical information on Dickens to social and cultural history to literary criticism and literary history. It embodies traditional approaches - literary influences, themes, imagery, characterization, setting, etc. - as well as more contemporary ones - feminism, post-structuralism, cultural studies, etc. Some of the material provides factual information (a definition of bildungsroman, a description of Utilitarianism, a brief history of the British empire) while other documents contain interpretive commentary on the novel (the use of the Prodigal Son motif, the depiction of female aggression, the question of what makes the gentleman). Links enable the reader to move quickly between related parts of the Web.

Like any Storyspace hypertext, The Dickens Web is not made solely to be read. Users can edit existing text, construct additional links, and incorporate completely new material that in turn can be linked to other parts of the Web.

Landow seems to have designed The Dickens Web primarily for use as an out-of-class resource in an introductory literature course. With upper-level students and the luxury of a computer classroom, I configured my course differently. We focused on just two novels: Great Expectations and George Eliot's Middlemarch. During the first two weeks of the semester I introduced the students to e-mail and the campus network, the World Wide Web, Storyspace, and The Dickens $W e b$ itself. Then we spent several weeks on Great Expectations, utilizing the Web both to stimulate classroom discussions and for short homework assignments. Instead of writing a traditional paper, the students either composed new material to add to the Web or expanded existing material, and they created hypertext links between their work and the rest of the Web. This project could, and in most cases did, involve some research, but the focus was on textual analysis and interpretation. In the second half of the course, the class discussed Middlemarch and then constructed its own Web for that novel. This writing project was longer than the first and had to involve research as well as textual analysis.

Since I employ a variety of interactive techniques in my traditional classroom, adapting The Dickens Web for class discussions was an easy task. Typically, I used the Web to initiate or complicate a discussion. Instead of defining the bildungsroman myself, for example, I had the students read the material in the Web and then discuss in small groups the specific ways in which Great Expectations fulfilled the criteria offered there, particularly in terms of education and vocation. After comparing the groups' conclusions, I invited them to read the brief essay in the Web on Utilitarianism and Dickens's opposition to it. I asked them if and how Dickens's view of Utilitarianism could be reconciled with his emphasis on work and vocation, which in turn facilitated a discussion of the novel's view of the individual in relation to the society.

Homework assignments were designed to provide practice at navigating through the Web and to initiate thought about the novel's various aspects. Again, most of my classes incorporate some form of directed but informal out of class writing, so at one level this simply involved incorporating the Web into that type of short assignment. But at another level I tried to exploit the specific opportunities that following links in hypertext creates. On one occasion I modified an existing assignment in the Web, asking the students to read 
the material on "Public Health" and "Race and Class" and then to locate a passage from the novel that was illuminated by the Web material, and to explain how. On another occasion I asked them to read the material in the "Religion" writing space and then to construct two links to other parts of the Web, explaining what they had learned from doing so, how their understanding of the novel had changed. In a third assignment I asked them to start anywhere in the Web and follow a series of three links, again explaining what the links had revealed to them.

It was in the two writing projects, however, that I most attempted to integrate the Webs into the students' thinking. For the Dickens project, I encouraged them not to approach their work as a traditional paper but to present it in whatever way they thought would be most effective in the Web. They could, if they chose, divide their project into multiple text spaces. For example, they could place historical information in one space and critical analysis in another, or lengthy passages from various critics and their response to those passages in separate spaces. In addition, they were required to construct both basic links and text links to connect their material to the existing parts of the Web, and to explain what a future reader of the Web would gain, in terms of understanding of the novel, from following them.

The project for The Middlemarch Web had similar requirements, but since this Web was constructed from scratch, there were several differences. The class members first discussed what this new Web should contain, agreeing on its basic parameters. With no existing information on Eliot to guide them, they were more dependent on their peers, and they had to learn about the nature of other people's projects to be able to determine what their own project could and should be linked to. For the group of students interested in Eliot's life and the novel's depiction of women - her relationship with Lewes, her views on "the Woman Question," the assessments of Middlemarch by modern feminist critics, etc. - such interaction was especially fruitful and the identification of potential links easy. Some students, however, like one working on Eliot's chapter epigraphs, had to remain content with constructing links within their own material.

\section{General Assessments}

The Dickens Web proved to be a successful teaching tool in many respects. By making such a range of infor- mation available in a novel format, the Web exposed the students to more contextual material than they are usually interested in reading - a striking confirmation of what Landow regards as one of hypertext's greatest strengths. ${ }^{1}$ In my experience, most students fail to utilize, or at least to utilize adequately, the editorial and critical apparatus designed to bridge the gap between past and present. This is true even when I assign - and incorporate into the class in various ways - readings from a work like Robin Gilmour's The Intellectual and Cultural Context of English Literature, 18301890. Since our curriculum stresses such context, this has proven especially frustrating for me. The Dickens $W e b$, however, managed to engage the students $-42 \%$ remarked on their course evaluations that it exposed them to a wider array of materials and approaches than they were used to. Their willingness to explore the Web's contextual material was, I think, facilitated not only by the ease of access but also by the atomistic quality of most of the Web's information. The short documents, often covering a complex topic like "Humor in Dickens" or "Public Schools" in a single, clearly labelled writing space, were informative but easy to digest. While there are obvious potential dangers in relying on what might be called "sound-bite scholarship," the Web mitigates this by incorporating sources directly, citing them prominently, and linking them to a fairly extensive bibliography.

The exposure to this range of material also generated paper topics that were more focused and more interesting, both for the students and for me. One of the dilemmas I consistently face in a course that requires a research project is how to provide students the freedom to choose a topic that interests them while avoiding the vague and sweeping proposals that unlimited possibilities tend to invite. Whether they are listening to a lecture, following a discussion, or even reading criticism, students tend to see only the results of research, not the process of it, and hence they lack models both for the kinds of research questions they can ask and for the ways to answer them. The diversity of material in The Dickens Web - presented, I think crucially, in a compact visual form - provided them with just this kind of model. A number of students chose historical projects, usually linked in some way with the novel's themes: Newgate Prison and confinement, Australia and the function of empire, sanitation in the Thames marshes and the social metaphor of disease. A paper on Dickens and Harriet Beecher Stowe that could have been a rather pedestrian comparison of their sympathy for the downtrodden became instead, thanks to the 
Web's material on social class, a discussion of the limits of Dickens's sympathies for the working classes in contrast to Stowe's more radical ideology. Another paper on Pip's relationships with Estella, Biddy, and Miss Havisham became, with the prompting of some of the Web's material on women and economics, a much more sophisticated analysis of the novel's messages about women's roles. Even a more traditional exercise in close reading like one student's examination of the novel's allusions to Hamlet was enriched by links to information elsewhere in the Web on literary history and the father-son relationship. Significantly, $42 \%$ of the students said in their evaluations that their research projects were more interesting to them than usual.

Perhaps the most striking confirmation of the possibilities that the Web opened up for students was what they didn't choose to write on: Dickens's life. Many students seem to believe that a work of literature is ultimately reducible, in some relatively straightforward way, to the writer's life. In the Web, however, the biographical material on Dickens was accorded no special status; hierarchically it was on the same level with "Science and Technology," "Literary Relations," and "Genre and Mode." Indeed, it took some prompting on my part to get the students to consult Dickens biographies and the Dickens letters for specific biographical information relevant to their projects: What were Dickens's views of transporting convicts to Australia? Did Dickens correspond with Stowe about Uncle Tom's Cabin? What was Dickens's opinion of Hamlet? Once prompted, however, they began to use the biographical material as a tool to help them interpret the novel. The student writing on Australia, for example, was puzzled why Dickens criticized the penal system's treatment of Magwitch and then made him a virtual poster-boy for rehabilitation and financial success. But when she learned of Dickens's view of the empire as a place where social outcasts could be sent to make a fresh start, this apparent contradiction was transformed into consistency.

As such examples suggest, the students increasingly approached their writing projects in ways that the hypertextual medium facilitated. In particular, they saw their projects as connected to other, sometimes very different, parts of the Web; in several cases they became interested in and made links to the work of other students in the class. A student working on Dickens's depiction of Joe Gargery's working-class dialect, for example, was surprised to find that her project had parallels with the project on Dickens and Stowe as well as another on utilitarianism and the novel's treatment of industrial versus mercantile capitalism. For The Middlemarch Web, a student working on medical education linked her material to another's work on the 1832 Reform Bill to show how the training of the various medical men in Middlemarch signals both their social status and political views. By that point in the term, many of the students were employing the conceptual language of hypertext, and that language had in turn encouraged intellectual interaction and collaboration among them.

Such successes, of course, were difficult to come by and were by no means uniform. Like any new writing medium, hypertext demands, as Landow and Jay David Bolter have stressed, the reconceptualization of what it means to read and write. For most students, and certainly at least for the immediate future, this reconceptualization will have to occur in the classroom, and it won't occur magically. It will have to be taught and learned.

This is perhaps best seen in the case of links, which Landow calls "the essence of hypertext technology" (186). The mechanics of links did not pose significant problems for the students. Following a link was a simple matter. While constructing a link was more cumbersome, with practice they became reasonably proficient at this as well. The difficulty was with what to do with a link once they had followed or constructed it. In obvious cases where the content was clearly related at a general level, they had no trouble. It was easy to see why the "Dickens and Darwin" writing space was linked to the "Darwin's Origin of Species" writing space, or why clicking on the term "Reform Act" in the "Chartism" text space would take you immediately to a text space explaining what the Reform Act was. But what they often could not see, especially at first, was how a piece of information mattered to the novel, how it could affect our reading or understanding of Great Expectations itself.

Let me provide an example. On the early homework exercise in which the students were to explain how following a link had affected their understanding of the novel, most provided a tautological answer: "Reading the material about prisons helped me because there are prisons in the novel, and knowing about them helps me understand why they are there." On the exercise in which they were to explain how a series of links had affected their understanding of the novel, only two or three students actually followed a series of links. The rest followed three different links from the same starting point, thus suggesting that their basic concept of a link was limited to a direct, one-step movement. 
Here, too, the same difficulty in explaining the link's significance to the novel was evident.

When we discussed this during our next class session, I asked the students to examine some of the materials in the Web on women's history and feminism. Then we followed a series of links from an essay on "Difficulties in Childbirth" to one on "Sanitation and Disease in Rich and Poor" to one on "Queen Victoria." I invited them to brainstorm about the connections among these writing spaces - what they revealed when taken as a group - and about possible connections to Great Expectations. They simply could not come up with anything - even when I prompted them with a character like Mrs. Joe to focus on. "What connection could there possibly be between Mrs. Joe and Queen Victoria?" asked one student in genuine exasperation. This question led many of the students to complain that very little of the material in the Web seemed to be connected to the novel at all.

The students' response revealed much about their assumptions. For them, The Dickens Web was a reference tool, not a pedagogical one. In Delany and Landow's terminology, they treated the hypertext as a "resource" (information provided by experts for extraction by individual users) rather than as an "environment" (a shared body of knowledge that users continually reshape) (Delany and Landow 32-33). It was supposed to provide them with answers, or at the very least with the questions. They approached it in a fundamentally passive way and hence were annoyed rather than gratified by the freedom it provided. Landow argues that from hypertext's emphasis on the active reader "follows a conception of an active, constructivist learner" (121). My students' response to hypertext, however, suggests that active reading and active learning are not, in practice, the necessary or immediate outcomes of the encounter.

The ability to link what is not explicitly related, and especially what appears unrelated, requires considerable cognitive sophistication. Landow acknowledges this: "[p]erceiving possible connections and arguing for their validity," he writes, "is a high-level intellectual skill" (136). As skilled readers and critics, we can see the possibilities for this that hypertext affords, but Landow goes further, arguing that hypertext enables "a novice reader to learn the habit of nonsequential reading" (126), to "quickly and easily learn the culture of a discipline" (128). My own experiences support Landow's fundamental point, but they also question just how "quickly and easily" this process occurs. My students often struggled just to process the material at the two ends of a link, and hence they tended to see the abyss rather than the bridge. And the medium itself, the mere mechanical ability to cross the bridge almost instantaneously, did not guarantee that the more important conceptual crossing would occur, even with the kinds of exercises Landow describes. By making it easier to ask our students to read and think in these more sophisticated ways, hypertext also increases our responsibility to teach them how to do this.

My own efforts along these lines largely underscore the difficulties. Even after our class discussion about Queen Victoria and Mrs. Joe, the students' explanations and justifications of the links for their Web projects remained heavily tautological. And the projects themselves, even when most interesting, tended not to link contextual material and novel very successfully. Students took advantage of the opportunity to present their work in non-traditional ways by dividing it, usually, into two separate writing spaces, one devoted to historical or critical or biographical information and the other devoted to their discussion of the novel. Almost invariably, their presentation of contextual material was remarkably effective. They reduced complex arrays of information into clear, concise, and relevant mini-essays. But just as invariably, their textual analyses remained at a general level, rarely focusing in detail on, or commenting on the significance of, the passages most relevant to the contextual material. It took two drafts for the student who wrote on the experiences of convicts in Australia to actually analyze Magwitch's account of his experiences. The person who wrote on Hamlet initially did not discuss the production of the play that Pip attends, and he could never really explain how it was connected, on a thematic level, to the rest of the novel. On Middlemarch, a student who researched the competing theories about the treatment of fevers had to be coaxed into examining the passages where Lydgate defends his practices against those of his colleagues.

Nonetheless, there is reason for optimism. The students did improve, and some eventually were able to articulate a fairly sophisticated argument about the significance of their material for the novels. One exercise, involving not The Dickens Web but the World Wide Web, offers an example of how this intellectual maturation may be accelerated. During our discussion of Great Expectations, I asked the students to access and explore a Web site devoted to an exhibition at the University of California-Berkeley's art museum on "The New Child: British Art and the Origins of Modern Childhood, 1730-1830." The exhibition argued that 
our modern conception of childhood as a special, innocent period around which family life revolves was a construction of the Enlightenment and a radical departure from the earlier paradigm in which children were viewed merely as small versions of adults (see Steward). After reading the exhibition's text and viewing its images, the students were to explain what relationship Dickens's depiction of Pip's childhood bore to the exhibition. Virtually every student saw that Pip's childhood departed from that of the "new child," but many also went further. Some recognized the importance of class issues, arguing that since Pip came from a working-class family rather than a bourgeois one, he was less the exception than he might appear. Others were even more perceptive, contending that Dickens exploited this conception of the "new child" as a standard against which his audience would assess Pip's experiences and, thus, sympathize with them.

Why did this exercise produce such impressive responses when similar exercises that also included meaningful but informal writing about the significance of links did not? There are, I think, two reasons. First, the assignment was focused exclusively on the activity of making conceptual links - it was not seen by the students as an ancillary component of a larger activity. Second, it was directed - the students were given two specific things to link, the exhibition's argument and Dickens's depiction of Pip's childhood. Additional exercises of this type early in the term, employing materials either within The Dickens Web or outside it, could gradually yield to the more open-ended assignments in which students make their own links and determine their own connections.

\section{Using The Dickens Web for Research}

Using The Dickens Web for research projects, even limited ones, places heavy demands on the students. Despite restricting myself to two novels, as opposed to the six I would assign in a traditional course on the Victorian novel, I overestimated what the students could handle. If they must learn to write as well as read in the hypertext - to add and edit writing spaces, text spaces, and links - class time must be devoted to demonstrating these procedures and allowing the students to practice them. ${ }^{2}$ This is especially true of the mechanics of adding material to the Web, which was not easily grasped, especially by those students whose familiarity with computers was limited. Story- space contains an import function that enables text files to be copied into a Web, but we encountered a number of difficulties with this. ${ }^{3}$ The effort that must be devoted to learning the technology - and battling with the glitches, frustrations and uncertainties that are a seemingly inevitable component of a campus computing environment - does distract students from the content of the course. (In their course evaluations, only half characterized the software as easy to use, and $20 \%$ felt that the technology had diminished or impeded their learning experience.) Once learned, moreover, these skills need to be reinforced - incorporated wherever possible into classroom activities as well as homework exercises.

The Web does not, of course, make students better researchers. The student interaction it is designed to foster is not specifically oriented toward research, although that seems to me to be where the pedagogical logic as well as the pedagogical excitement of hypertext should lead us. The bibliographies in The Dickens $W e b$ are a useful resource and can help to initiate some student projects, but the need for extensive and on-going student-instructor consultation remains essential. Although topic selection was easier and the topics themselves were more interesting, narrowing the topic, locating and evaluating sources, and employing those sources in cogent, sensitive, and detailed textual analysis was as much work for me and for the students as it always is. In assigning two writing projects, even though one was only five pages and the other only seven, I assigned too much.

Even so, one of the great potentials of hypertexts is that they can be added to and re-used. The material that my students added to The Dickens Web will be available to-future classes. The web that they began for Middlemarch will provide information that next year's students can both use and augment. Alternatively, I can construct webs myself for this or other courses; if any of my colleagues are interested, we could develop webs for related classes, and then invite students to utilize the other class's web. The possibilities for integrating various courses - not merely within English but across disciplines and even across university lines - are limitless.

My experience, however, suggests that here, too, there is reason for lowered expectations, at least initially. Considerable research in composition studies indicates that student writing improves when students write for "publication" - that is, when their writing has a real audience that is going to use it. I thus made clear to my students from the beginning that their work was 
being written for the web, and that future classes would read it. This seemed, however, to have no discernible effect. Indeed, one student asked in class, with others nodding in agreement, why they should have to do the work that others would benefit from?

A more significant dilemma was posed by the competing demands of inclusiveness and quality, a dilemma that Landow tends to gloss over at both the theoretical and practical levels, particularly in Hypertext. ${ }^{4}$ On the one hand, I wanted all my students to have the opportunity to add their work to the Web; on the other, the fact that this material would be accessed by future students compelled me to play an aggressive gate-keeping role. As I graded the first set of projects, I realized that several would require massive revision to be acceptable candidates for the Web - they were simply too incoherent and/or contained too many interpretive or factual errors. A large number of others, usually in the low to mid $B$ range, showed promise but needed further work to be effective pieces of the Web. Should I let all this work be imported into the Web? Should I permit some to be added and some not? Should I allow all the work to be added but then delete what I regarded as substandard after the term? None of these options was appealing. Ultimately I decided to give all students the option to revise and resubmit for a higher grade, explaining why I wanted to reserve the right to determine which projects should be added to the Web. Both the students' acceptance of this policy and the decision by many of them to revise further confirmed that it was the grade, not the prestige of publication, that motivated them.

A better procedure would be to assign only one research project, make clear from the outset that publication in the Web is the goal but is not guaranteed, and give an "editorial board" of students (with me as a consultant or a member) responsibility for determining which projects merit publication. This would not eliminate all the dilemmas, obviously, but it would make the students owners of the process while maintaining high quality standards. Focus on one project would permit significant development by every student, especially those who have good ideas but need encouragement and assistance to bring them to fruition. The prestige of publication, perhaps buttressed by bonus credit for those published, might provide the additional incentive that the other format did not.

\section{Theoretical Implications}

Hypertext enthusiasts, particularly Landow, Jay David Bolter, and Richard Lanham, see it as a liberatory medium. Information that is produced and disseminated electronically is more accessible and more likely to escape the control of existing authority: "the logic of information technologies," writes Landow, "which tend toward increasing dissemination of knowledge, implies increasing democratization and decentralization of power" (169). Individual readers of hypertext, freed of the tyranny of linear structures and authorial control, are able to determine their own reading experiences by pursuing the paths that interest them. According to Bolter, "[t]he computer makes visible the contest between author and reader that in previous technologies has gone out of sight." Whereas the author "has always before had the upper hand," the "electronic medium challenges all ... attempts to circumscribe the reader's participation" (154-55; emphasis added). Because electronic writing "opposes standardization and unification as well as hierarchy," any loss of a "coherent cultural tradition" is more than compensated for by "the freedom to establish our own traditions in miniature" $(233,238)$. In the classroom, electronic textbooks promise, in Lanham's words, "a radical democratization ... that allows every student to walk an individual path" (23). Similarly, Landow argues that hypertexts "intrinsically promote a new kind of academic freedom and empowerment" and that this empowerment "has always marked applications of new information technology to education" $(177,174$; emphasis added). Indeed, says Landow, the scariest feature of hypertext for teachers may be the way it "answers teachers' sincere prayers for active, independent-minded students who take more responsibility for their education and are not afraid to challenge and disagree" (163).

Such claims for the democratizing, empowering tendencies of information technologies generally, hypertext in particular, clearly have both a theoretical and a historical basis. In attempting to overcome the Luddite propensities of humanists, however, Landow, Bolter, and Lanham press their case too far. As Richard Grusin has argued, they tend to be guilty of what Grusin calls "the technological fallacy": the ascription of agency, especially political agency, to technology itself (470). I would like to offer, briefly, a similar critique from the practical perspective of my classroom experiences. 
As Foucault demonstrates in Discipline and Punish, efficient structures of surveillance and control are both pervasive and invisible. While hypertext provides the reader with more options and more control over the reading experience, the technology also can facilitate the disguising of authorial control. Storyspace's main "views" - map, chart, outline, and tree map - all involve hierarchy, and the reader's options for following links are dependent, at least at the outset, on the links that the author has established. It is, in other words, the author who determines the powerful initial configuration of the hypertext: how the writing spaces are organized, what material merits linkage, etc. ${ }^{5}$ Storyspace even has a feature called a "guard field" that enables the constructor of links to force the reader to travel in a particular direction or to follow links in a certain order. This is to say simply that hypertext authors cede less control to the reader than is usually admitted; that the hypertext reader's choices are constrained, though constrained differently, than in printed works; and that hypertext itself is not inherently or necessarily democratic or anti-hierarchical. ${ }^{6}$

My students' encounters with hypertext confirm that liberation does not occur automatically. Their initial passivity towards The Dickens Web, as well as their difficulties in explaining the significance both of pre-set links and of their own, indicate that students must be taught how to read hypertextually. With the need to teach comes, inescapably, issues of authority and the appropriate balance between the students' autonomy and the instructor's control. In the same way that the electronic author arguably cannot simply abdicate responsibility for providing structures by which the reader can make sense of the hypertext, instructors who ask their students to participate in the construction of hypertexts cannot simply adopt an "anything goes" mentality to their contributions. While some faculty may really not want Landow's active, independent, subversive hypertextual student, my dilemma was more mundane but also, I think, more representative: what to do when students aren't active and independent and subversive.

This dilemma is exacerbated by problems of access to the technology, not just in the present and future, but in the past, for access is itself a political and economic issue. Landow is well aware that the potential of hypertext depends on access to it (186), but he seems to see elite institutions, not less prestigious ones that place greater emphasis on teaching, as facing a more daunting immediate obstacle in their "general lack of concern with pedagogy" (161). However, even when an institution has the resources to provide the necessary hardware and software, there are still significant differences to be overcome. Students at elite institutions are more likely to have worked with computers prior to college and are more likely to own or have ready access to a computer, often in the residential setting of the university. ${ }^{7}$ At a commuter campus like mine, with a sizable percentage of non-traditional students and an even larger population of working students, utilizing computers posed access difficulties for many students and basic technical ones for those unfamiliar with the technology. For my students, working with The Dickens Web meant coming to campus and using a crowded computer lab. A number of them, in particular the older students, had little or no prior experience with computers at all and thus had to learn basic computer argot and mouse techniques. "Empowerment" is not the word that these students used to describe their encounter with hypertext, yet their situations and experiences are, I venture to say, more representative than the situations and experiences of students at elite institutions. Literature instructors who plan to incorporate computers and hypertexts like The Dickens Web into their teaching should thus be prepared for these kinds of very practical obstacles.

If paeans to the pedagogical potential of hypertext have been exaggerated, and if its difficulties and problems have tended to be minimized, it is nonetheless possible to overcome at least some of the difficulties and to realize at least some of the potential. For me, The Dickens Web resolved several of the central challenges of the student-centered classroom. That it also created or heightened others is only to be expected - and is a necessary step towards their resolution. The opportunities it created for active learning, for collaboration, and for the presentation of contextual materials made it worth using, and worth continuing to use. Hypertext in the teaching of literature, in short, is not all hype.

\section{Notes}

1 Landow, Hypertext 126, 187. All subsequent citations from Landow in the text are from this work.

2 The ability to project the instructor's screen is, in my view, essential here. Link construction in particular is not intuitively obvious in Storyspace; verbally describing such procedures with adequate clarity is thus extremely difficult. Students need to be able to see the instructor do it before trying it themselves.

3 Our computer staff were unable to determine the cause of these difficulties, but it seemed to be true only with the version installed on the server. The problem, of course, is that for student work to be made available to other student readers of the Web, it has to be 
added to that commonly accessible copy. Text can be typed directly into the Web, but we found this to be slow on the server version, and we experienced similar problems when trying to save the work.

4 Elsewhere, Landow admits that "[i]n practice, the freedom of interactive users will probably need to be restricted," that "workable hypermedia requries some central editorial control" and "some provision for re-setting the environment to the structure first presented by its designer." The key mechanism for this control is "hierarchies of permissions" in which the author controls who is able to do what to the hypertext (Delany and Landow $21,35,36$ ).

5 As Delany and Landow acknowledge in passing, "[d]ecisions about relevance obviously bear heavy ideological freight, and hypertext's very emphasis upon connectivity makes the absence or exclusion of texts far more significant than it would be in print technology. ... [E]xcluding any particular bit of text from the metatext makes it drop relatively much farther out of sight" (31).

6 Concomitantly, despite their generally sensitive historical contextualization of the acts of reading and writing in relation to the changing technologies of production, Landow, Bolter, and Lanham tend, it seems to me, to oversimplify the degree to which the reader of printed books has been at the mercy of the author.

7 A recent government survey reports that the number of public schools with Internet connections is increasing, but that the percentage among wealthy schools is twice that for low-income schools ("Public Schools"). Significant differences also exist depending on a school's size, location, and level of minority student population.

\section{References}

Bolter, Jay David. Writing Space: The Computer, Hypertext, and the History of Writing. Hillsdale, NJ: Erlbaum, 1991.

Delany, Paul, and George P. Landow. "Hypertext, Hypermedia, and Literary Studies: The State of the Art." In Hypermedia and Literary Studies. Ed. Delany and Landow. Cambridge and London: MIT P, 1991, pp. 3-50.
Foucault, Michel. Discipline and Punish: The Birth of the Prison. New York: Pantheon, 1977.

Gilmour, Robin. The Victorian Period: The Intellectual and Cultural Context of English Literature, 1830-1890. London and New York: Longman, 1993.

Grusin, Richard. "What is an Electronic Author? Theory and the Technological Fallacy." Configurations 2 (1994): 469-483.

Landow, George P., Ed. The Dickens Web. Diskette. Cambridge, MA: Eastgate, 1992.

Landow, George P. Hypertext: The Convergence of Contemporary Critical Theory and Technology. Baltimore and London: Johns Hopkins UP, 1992.

Landow, George P., Ed. The Victorian Web. N.D. Online. Available HTTP: http://www.stg.brown.edu/projects/hypertext/landow/ victorian/victov.html. 18 Feb. 1996.

Landow, George P. and Jon Lanestedt, Eds. The In Memoriam Web. Diskette. Cambridge, MA: Eastgate, 1992.

Lanham, Richard A. The Electronic Word: Democracy, Technology, and the Arts. Chicago and London: U of Chicago P, 1993.

"Public Schools Increase Links to Cyberspace." New York Times 18 Feb. 1996, natl. ed., sec. 1: 16.

Steward, James. The New Child: British Art and the Origins of Modern Childhood, 1730-1830. Berkeley: University Art Museum/Pacific Film Archive, 1995. Online. University of California-Berkeley Art Museum. Available HTTP: http:// www.uampfa.berkeley.edu/exhibits/newchild. 18 Feb. 1996.

Storyspace. Vers. 1.0.9 for Windows. Diskette. Cambridge, MA: Eastgate, 1995. 